\title{
PENGUATAN LITERASI PEREMPUAN PADA KADER MASYARAKAT KOTA MOJOKERTO MELALUI PENERBITAN TABLOID SUHITA
}

\author{
Azizatuz Zahro ${ }^{1}$, Lisa Sidyawati ${ }^{2}$, Ludi Wishnu Wardana ${ }^{3}$, Subhan $^{4}$, Vira Setia Ningrum ${ }^{5}$ \\ ${ }^{1}$ Jurusan Sastra Indonesia, Fakultas Sastra, Universitas Negeri Malang \\ ${ }^{2}$ Jurusan Seni dan Disain, Fakultas Sastra, Universitas Negeri Malang \\ ${ }^{3}$ Jurusan Pendidikan Ekonomi, Fakultas Ekonomi, Universitas Negeri Malang \\ ${ }^{4}$ MTs Negeri 2 Kota Malang \\ ${ }^{5}$ Tenaga Kependidikan, Fakultas Sastra, Universitas Negeri Malang \\ email: azizatuz.zahro.fs@um.ac.id
}

\begin{abstract}
Abstrak
Penguatan literasi perempuan melalui penerbitan tabloid Suhita ini dilakukan pada kader masyarakat kota Mojokerto. Mereka adalah aktivis yang menjadi kader KB, kader Posyandu Balita, dan kader Posyandu Lansia. Penguatan literasi dilakukan untuk mendukung tugas-tugas mereka sebagai kader masyarakat. Dalam penguatan literasi ini peserta dibekali dengan berbagai teknik jurnalistik dan teknik menulis untuk mendukung kompetensi lisan mereka yang amat penting dimiliki seorang kader masyarakat. Kegiatan belajar dilakukan dengan menggunakan strategi hasil adaptasi jigsaw. Peserta dibagi dalam kelompok-kelompok sesuai jenis tulisan dan dilakukan penggantian tugas menulis pada tiap pertemuan. Kelompok tersebut antara lain kelompok profil, kelompok berita, kelompok opini, dan kelompok seni/hobi. Dengan demikian, dalam 4 kali pertemua masing kelompok telah menulis 4 jenis ragam tulisan. Pembelajaran yang demikian menjadikan suasana belajar hidup karena pembelajar diperlakukan sebagai orang dewasa yang penuh prakarsa dan mandiri. Hasil kegiatan berupa tulisan-tulisan yang siap dipublikasikan karena penyuntingan juga dilakukan bersama pada tiap pembelajaran. Penyuntingan dilakukan dalam kelompok baru. Kelompok baru dibentuk dengan cara kelompok asal membagi diri dalam kelompokkelompok baru. Hasil belajar diterbitkan dalam tabloid 16 halaman yang diberi nama nama Suhita. Nama Suhita diambil dari nama Dyah Suhita yang merupakan ratu Kerajaan Majapahit yang sangat baik sebagai sumber inspirasi.
\end{abstract}

Kata kunci:literasi perempuan, kader masyarakat, Suhita

\begin{abstract}
Strengthening women's literacy through the publishing of the Suhita tabloid was carried out to community cadres in Mojokerto. They are activists who become KB cadres, Posyandu Toddlers cadres, and Posyandu Elderly cadres The enhancement of literacy was put through in order to sustain their position as group cadres. Participants were provided with different journalistic techniques and writing techniques to improve their oral abilities, which are very important to the group. Learning tasks were accomplished using a jigsaw adaptation technique. Participants were split into classes according to the form of writing and the written task was substituted at each meeting. These included profile groups, press groups, viewpoint groups and arts/hobby groups. Thus, in four sessions, four styles of writing were written by each party. This kind of learning made the learning environment alive, because learners were treated like adults who are full of initiative and freedom. The outcomes of the exercise were in the form of writings ready to be written, since editing was often carried out together in each lesson. Editing has been performed in a new batch. New groups were formed by the original group, which was split into new groups. The learning outcomes were reported in a 16-page tabloid called Suhita. The name Suhita was taken from the name Dyah Suhita, who was the queen of the Majapahit Kingdom, a very good source of inspiration.
\end{abstract}

Keywords: women's literacy, community cadres, Suhita 


\section{PENDAHULUAN}

Literasi sangat penting dalam kehidupan. Kemampuan literasi dianggap berkorelasi terhadap kualitas hidup manusia sepanjang hayat. Menurut Baynham (1995) seseorang dikatakan literat apabila ia memiliki pengetahuan dan kemampuan yang benar untuk digunakan dalam setiap kegiatan yang menuntut fungsi literasi secara efektif dalam masyarakat; dan keliteratan yang diperolehnya melalui membaca, menulis, dan aritmetika itu memungkinkan untuk dimanfaatkan bagi dirinya sendiri dan perkembangan masyarakatnya.

$\begin{array}{llr} & \text { Penguatan literasi pada semua } \\ \text { pihak harus dilakukan, termasuk } & \text { thaniki } \\ \text { perempuan. } & \text { Perempuan memiliki }\end{array}$ kedudukan yang strategis di masyarakat. Secara sosial, perempuan pada umumnya lebih dekat dengan anak-anak dan lingkungan. Menggiatkan literasi perempuan berarti juga menggiatkan literasi di lingkungan keluarga maupun masyarakat.

Salah satu kelompok masyarakat yang penting ditingkatkan literasinya adalah kader masyarakat Kota Mojokerto. Para kader KB, Posyandu, dan kesehatan ini merupakan aktivis pemberdayaan masyarakat. Mereka dikoordinasi oleh berbagai dinas, terutama oleh Dinas P3AKB (Pemberdayaan Perempuan, Perlindungan Anak dan Keluarga Berencana) dan Dinas Kesehatan. Mereka menjadi kader untuk menyosialisasikan berbagai program KB dan kesehatan, menginisiasi peniptaan lingkungan yang sehat, menjadi pengurus Posyandu anak maupun lansia, menjadi Bunda PAUD, dan berbagai kegiatan sosial lain.

Kader masyarakat dalam penguatan literasi perempuan melalui penerbitan tabloid Suhita ini adalah perwakilan dari kecamatan-kecamatan yang ada di Kota Mojokerto. Kota Mojokerto merupakan kota yang strategis seiring dengan pembangunan jalan bebas hambatan/jalan tol yang menghubungkan Mojokerto dengan kota-kota lain di sekitarnya. Kota Mojokerto dalam perkembangannya banyak dipilih sebagai kota hunian bagi para pekerja di kota industri Surabayadan Sidoarjo. Mojokerto yang tengah giat melakukan pembangunan segala sektor harus memiliki sumber daya manusia yang handal sehingga bisa menyelaraskan dengan perkembangan pembangunan yang sangat cepat.

\section{METODE}

Pengutan literasi ini merupakan pengabdian yang dilakukan dengan disain tindakan pada kelompok sasaran. Pentingnya kemampuan kader masyarakat Kota Mojokerto dalam mengampanyekan persoalan KB, kesehatan, dan sosial secara lisan dan tertulis menjadi dasar dilakukannya penguatan literasi ini. Penguatan literasi ini dilakukan untuk memperkuat pembekalan-pembekalan yang telah diberikan oleh instansi terkait sehingga mereka lebih mandiri dalam meningkatlan kompetensi.

Kegiatan dilakukan dengan membekali peserta dengan berbagai teknik jurnalistik dan teknik menulis. Kegiatan dilakukan dalam 6 kali pertemua atau setara 48 js. Kegiatan belajar dirancang dengan strategi kooperatif, yaitu belajar dalam kelompok-kelompok kecil sesuai pengelompokan rubrik atau jenis tulisan.

Desain kerja kelompok menggunakan model jigsaw dengan dua mekanisme, pembentukan kelompok asal (kelompok ahli/penulis) dan kelompok baru (kelompok penyuntingan). Kelompok asal disiapkan menjadi ahli menulis jenis tulisan tertentu. Jumlah kelompok sesuai pengelompokan jenis tulisan, yaitu (1) berita dan berita foto; (2) opini dan pengetahuan; (3) profil tokoh, usaha, sekolah dan Lembaga lainnya; dan (4) hobi dan seni: cerita, puisi, tips, serta resep.

Tiap anggota kelompok harus menyelesaikan sebuah tulisan hingga siap dipublikasi. Pada pertemuan berikutnya dilakukan penggantian tugas kelompok sehingga setiap peserta mempunyai beragam jenis tulisan untuk mengisi rubrik dalam tabloid. Topik yang diangkat tentang berbagai peristiwa di sekitar mereka, parenting, kesehatan, lingkungan, teknologi, dan kewirausahaan. Hasil belajar dipublikasikan dalam tabloid Suhita 16 halaman. Nama Suhita diambil dari tokoh Kerajaan Majapahit, salah satu kerajaan paling berpengaruh di Indonesia pada masa 
lampau. Kota Mojokerto diyakini sebagai pusat pemerintahan Majapahit dan Suhita adalah salah satu Ratu bijak yang pernah ada.Oleh karena itu, nama Suhita ini diharapkan menjadi sumber inspirasi sebagaimana Ratu Dyah Suhita yang religius, bijaksana, dan pendamai perang saudara. Suhita juga merupakan akronim dari Suara Hati Kita/Wanita.

\section{HASIL DAN PEMBAHASAN Proses Pembelajaran}

Peningkatan literasi perempuan melalui penerbitan tabloid Suhita dilakukan dalam 5 kali kegiatan belajar tatap muka. Materi belajar meliputi materi tentang jurnalistik, teknik menulis sesaui rubrik dalam tabloid, dan pengutan pengetahuan. Kegiatan belajar dilakukan secara kooperatif dan kolaboratif sebagaimana saran Slavin (2000) untuk memaksimalkan kinerja individu dalam sebuah kelompok belajar. Lebih lanjut, Slavin (2000) menegaskan bahwa strategi kooperatif penting untuk membangun kooperasi dan kolaborasi antaranggota kelompok. Prosedur kerja dalam pembelajaran kooperaatif diatur sedemikian rupa agar dapat memaksimalkan potensi semua anggota kelompok.

Dalam kegiatan pembelajaran untuk penerbitan tabloid Suhita, tiga indikator keberhasilan proses pembelajaran meliputi keaktifan peserta, keantusiasan peserta, dan kolaborasinya dalam kelompok. Kegiatan belajar dalam penguatan literasi melalui penerbitan tabloid Suhitaini dilakukan dengan membentuk 4 kelompok dengan anggota masing-masing 5 orang. Kelompok ini disiapkan untuk menjadi ahli menulis jenis tulisan tertentu. Karena banyaknya jenis tulisan, setiap kelompok mendapat tugas beberapa jenis tulisan sekaligus yang dikelompokkan berdasarkan kemiripan karakteristiknya. Misalnya, kelompok 1 ahli berita dan berita foto; kelompok 2 ahli opini dan pengetahuan; kelompok 3 ahli profil tokoh, sekolah, dan usaha; dan dan kelompok 4 ahli cerita, puisi, tips, serta resep. Tiap anggota kelompok harus menyelesaikan sebuah tulisan hingga siap dipublikasi pada tiap pertemua. Berikut ini gambaran pembagian jenis tulisan dan kelompok.

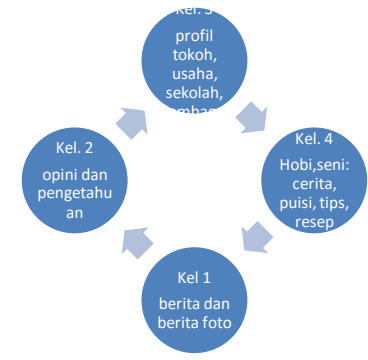

Gambar 1: Pembagian Topik dan Kelompok

Kooperasi dan kolaborasi dilakukan mulai tahap pramenulis, proses menulis, hingga pascamenulis. Pada tahap pramenulis, peserta curah pendapat saling menanggapi pilihan topik tulisannya dari segi kemenarikan, kebaruan, dan kemanfaatannya. Selanjutnya peserta mengembangkan tulisannya. Pada tahap pascamenulis, dilakukan penyuntingan bersama dengan menukar hasil karya dalam kelompok.

Untuk memberi pengalaman belajar yang lebih lengkap pada peserta, pada pertemuan berikutnya dilakukan penggantian tugas kelompok dan perbaikan pembelajaran berdasarkan evaluasi kegiatan sebelumnya. Dengan demikian, setiap peserta mempunyai beragam jenis tulisan untuk mengisi rubrik dalam tabloid dan pembelajaran semakin baik. Topik yang diangkat tentang berbagai peristiwa di sekitar mereka, parenting, kesehatan, lingkungan, teknologi, dan kewirausahaan.

Dalam kegiatan belajar juga disediakan berbagai sumber belajar, baik yang berasal dari internet, buku, maupun koran dan majalah. Ini karena kegiatan menulis tidak dapat dilepaskan dari kegiatan membaca sebagai sumber ide dan kreativitas. Peserta perlu didorong untuk memiliki kegemaran membaca dengan penyediaan bacaan yang bervariasi, menyenangkan, dan sesuai dengan subjek belajar. Pembelajaran dengan berbagai tema ini mengikuti saran Bamford dan Day (1998) untuk meningkatkan kegemaran membaca diperlukan sumber belajar yang bervarasi ragam dan temanya. Selain itu, sumber belajar menjadi bacaan yang akan memicu munculnya ide atau bisa juga sebagai model yang dijadiakan sumber belajar. Seperti yang dikatan Ismail (2003) menulis tak dapat dipisahkan dari kegiatan 
membaca. Membaca dan menulis dapat diibaratkan sebagai dua sisi mata uang, berbeda tetapi tak dapat dipisahkan.

$$
\text { Dalam pembelajaran untuk }
$$

penguatan literasi melalui penerbitan tabloid Suhita ini, ketergantungan peserta pada instruktur atau pembimbing juga dapat dikurangi. Seperti yang dikemukakan Zahro dan Sulistyorini (2010) bahwa strategi kooperatif dapat menambah kepercayaan kemampuan berpikir sendiri, menemukan informasi dari berbagai sumber, dan belajar dari sumber yang lain yang dikembangkan dalam kelompok. Suasana belajar juga menjadi lebih hidup karena pembelajar diperlakukan sebagai orang dewasa yang mandiri dan penuh prakarsa.

$$
\text { Kegiatan pembelajaran yang }
$$

dilakukan dengan strategi belajar yang bersifat kooperatif dan kolaboratif mampu menghidupkan kegiatan belajar sehingga semua peserta aktif, antusias, dan mampu berkolaborasi sehingga pembelajaran menjadi milik bersama. Pembelajaran kooperatif bukan sekedar belajar kelompok atau kelompok kerja (Slavin, 2000). Dalam penguatan literasi melalui penerbitan tabloid Suhita, tugas menyelesaikan satu jenis tulisan untuk mengisi rubrik dalam tabloid menjadi pendorong semua kelompok menyelesaikan tugas dengan baik. Hasil kegiatan berupa tulisan-tulisan peserta tersebut selanjutnya siap dipublikasikan karena penyuntingan juga dilakukan bersama dalam kelompok. Penyuntingan dilakukan dengan menukarkan tulisan antaranggota kelompok dan presentasi penyuntingan dalam kelompok. Berdasarkan tanggapan dari anggota kelompok yang lain tersebut, penulis memperbaiki karyanya. Pola kegiatan ini dilakukan dalam setiap kali pertemuan dengan jenis tulisan yang berbeda.

\section{Hasil Pembelajaran}

Hasil belajar dalam kegiatan penguatan literasi perempuan melalui penerbitan tabloid Suhita berupa karya tulis jurnalistik untuk mengisi rubrik-rubrik dalam tabloid. Sampul Suhita dapat dilihat pada gambar berikut.

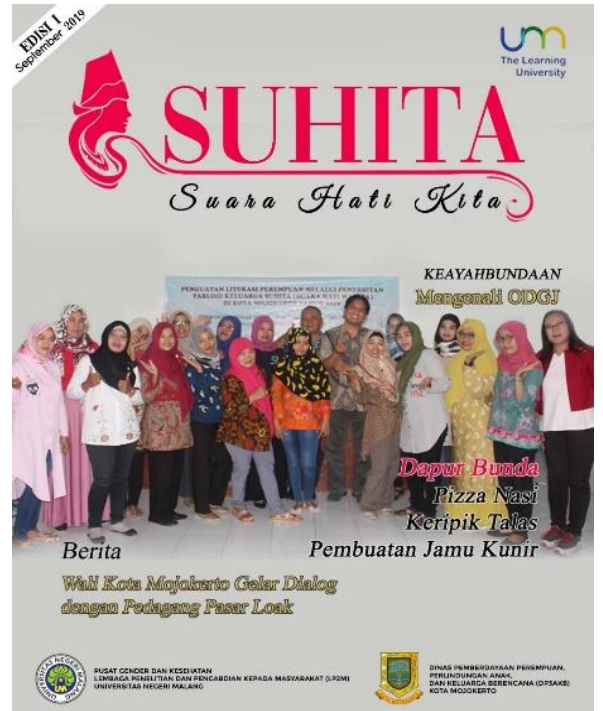

Gambar 2; Sampul Suhita

Karya tulis tersebut dikelompokkan menjadi 4 jenis, yaitu berita dan berita foto; opini dan pengetahuan; profil tokoh, sekolah, dan usaha; cerita, puisi, tips, serta resep. Tiap anggota kelompok harus menyelesaikan sebuah tulisan hingga siap dipublikasi pada tiap pertemua.

Indikator keberhasilan kegiatan belajar ini adalah peserta memiliki minimal 4 karya tulis dan karya tulis tersebut layak publikasi, yaitu (1) isinya menarik, (2) bahasanya mudah dipahami, dan (3) karya tersebut orisinil. Berdasarkan hasil belajar dapat disimpulkan bahwa 80 persen portofolio hasil karya tulis peserta lengkap. Mereka memiliki beberapa koleksi tulisan. Hanya 4 orang dari 20 orang saja yang portofolionya tidak lengkap atau tidak ada. Hal ini dikarenakan keterlibatan belajar mereka secara langsung (tatap muka) yang kurang karena kesibukan yang dimiliki.

Dari segi kualitas tulisan, hasil belajar peserta sebagian besar layak dipublikasi. Keterwakilan penulis dalam tabloid yang diterbitkan sebanyak $80 \%$. Hal ini dikarenakan tulisan dalam tabloid selain didasarkan atas proporsionalitas atau keterwakilan penulis dalam tablid, tulisan juga harus diseleksi. Perwujudan karyakarya peserta belajar dalam tabloid dapat dilihat pada gambar berikut. 


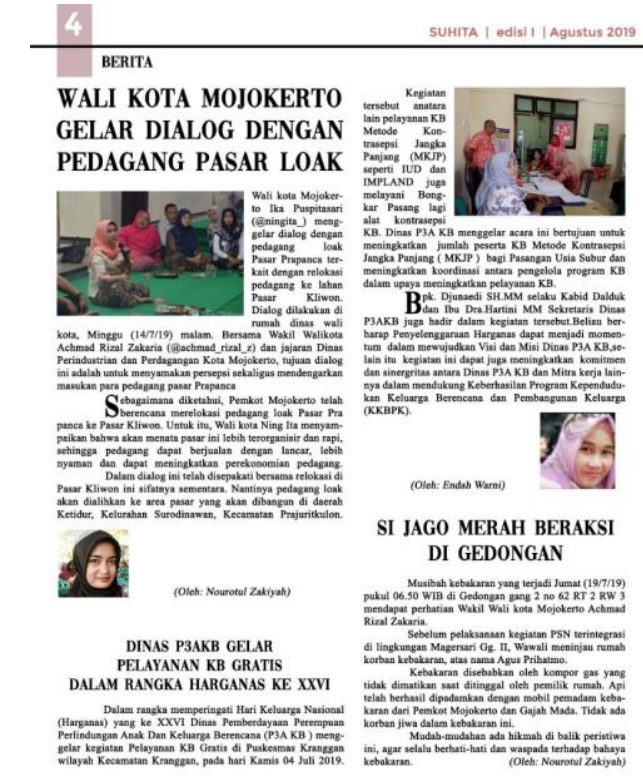

Gambar 3: Karya Tulis yang di muat dalam tabloid Suhita

Karya peserta kegiatan penguatan literasi meliputi semua jenis tulisan yang direncanakan untuk mengisi tabloid Suhita. Tabloid Suhita ini dirancang sebagai tabloid keluarga yang terdiri atas 16 halaman. Di antara 4 kelompok jenis tulisan, karya berita merupakan karya yang paling banyak memerlukan perbaikan. Kesulitan menemukan peristiwa bernilai berita dan mengemas berita lama agar tetap menarik dialami oleh sebagian besar peserta. Kesulitan ini diperbaiki dengan memandu kegiatan presentasi penyuntingan. Melalui balikan-balikan yang diberikan instruktur secara individual dalam bentuk koreksi, kesulitan tersebut dapat diatasi. Instruktur menyiapkan model atau contoh berita, cara menulis teras berita sebagai pusat berita, dan cara menampilkan keterangan waktu yang dituntut dalam berita agar berita tidak tampak basi.

Pola belajar menulis jenis tulisan yang lain juga dilakukan secara sama. Setiap pertemuan, kelompok mendapat tugas menulis jenis tulisan yang berbeda. Hasil karya mereka selanjutnya dipilih oleh redaksi untuk dimuat dalam tabloid Suhita. Redaksi terdiri atas pemangku kebijakan, pelaksana pengabdian/peneliti/instruktur, dan perwakilan peserta kegiatan. Ini dimaksudkan agar peserta intensif terlibat dalam kegiatan pembelajaran, sekaligus pengelolaan tabloid. Pewarisan pengalaman menyeleksi tulisan, mengatur, memandu layout tabloid, dan pengurusan perizinan melalui pelibatan peserta dalam pengelolaan tabloid dimaksudkan agar peserta juga memiliki pengalaman mengelola media.

Rubrik tabloid keluarga Suhita meliputi kolom redaksi, warta atau berita, kolom kesehatan, kolom pendidikan, kolom usaha, resep dan tips, profil tokoh, dari sekolah ke sekolah, kisah, puisi, dan galeri. Nama Suhita merupakan nama seorang ratu dalam sejarah kerajaan Majapahit yang diyakini sebagai Mojokerto di masa lampau. Suhita merupakan ratu perempuan kedua setelah Tri Bhuwana Tungga Dewi. Suhita dikenal sebagai ratu yang mampu menyelamatkan Majapahit dari pertikaian atau perang saudara. Kebijaksanaan Suhita ini diharapkan menjadi inspirasi bagi perempuan Mojokerto dan siapa saja untuk menjadi sosok yang mampu menjadi penyejuk di tengah banyaknya keragaman. Suhita juga merupakan akronim dari "Suara Hati Kita/Wanita".

Dengan penerbitan tabloid Suhita ini, berarti para kader KB dan kader kesehatan kota Mojokerto memiliki media belajar, berbagi pengalaman, berbagi kabar, dan berkomunikasi di antara mereka maupun seluruh lapisan masyrakat kota Mojokerto. Dengan penguatan literasi ini diharapkan mereka menjadi kader yang senantiasa terus belajar untuk meningkatkan kompetensinya. Membaca dan menulis sejak lampau diakui sebagai sarana seseorang dapat memperoleh ilmu pengetahuan dan pengalaman. Secara filosofis, disebutkan bahwa moral, pendapat, kebudayaan, ilmu pengetahuan, dan teknologi sampai ke tingkat perkembangannya yang sekarang ini merupakan akibat langsung dari pembacaan buku-buku yang diturunkan oleh Tuhan Yang Maha Esa dan karya manusia terkemuka (Oka dan Basuki, 1990). Oleh karena itu, kebiasan membaca dan menulis sangat penting diupayakan.

Menulis merupakan kegiatan mengekspresikan pikiran dan perasaan melalui tulisan. Menulis berarti juga berpikir. Oleh karena itu, keterampilan membaca dan menulis merupakan keterampilan yang secara langsung berhubungan dengan 
peningkatakan kualitas sumber daya manusia. Membaca dan menulis menjadi pintu bagi setiap orang untuk mempelajari segala hal

\section{KESIMPULAN}

Kemampuan literasi sangat penting di era kebebasan informasi agar tiap orang dapat bijak menyikapi informasi. Bagi kader kesehatan dan KB atau aktivis pemberdayaan masyarakat, kemampuan literasi juga penting karena kompetensi mereka sebagai aktivis pemberdayaan masyarakat harus terus diperbaharui. Dengan penerbitan tabloid yang direncanakan terbit setiap caturwulan, mereka memiliki media belajar yang berkesinambungan. Tabloid juga menjadi sarana mereka berkumpul untuk belajar, berdiskusi, dan berbagi informasi.
DAFTAR PUSTAKA

Baynham, Mike. 1995. Literacy Practices: Investigating Literacy in Social Contexts. London: Longman.

Bonilla, W.J.E. dan Barbara Werchadlo. 1995. Literature Response Journalis In A First-Grade Clasroom. Dalam Language Arts. Volume 72. No 8, Desember 1995.

Day, R., Richard and Bamford, Julian. 1998. Extensive Reading in the Second Language Classroom. USA: Cambridge University Press.

Ismail, Taufik. 2003. Agar Anak Bangsa Tak Rabun Membaca dan Tak Pincang Mengarang. Pidato Pengukuhan Doktor Honoris Causa di Universitas Negeri Yogyakarta (UNY).

Oka, I.G.N dan Basuki. 1990. Retorika, Kiat Bertutur. Malang: YA3.

Slavin, R.E. 2000. Cooperative Learning. Maryland: Jhon Hopkins University.

Zahro, Azizatuz dan Sulistyorini, Dwi. 2010. Srategi Kooperatif dalam Pembelajaran Menyimak dan Berbicara. Malang: A3 